\title{
Model Pembelajaran Pendidikan Multikultural melalui Pendekatan Proyek Kolaboratif
}

\author{
Roostrianawahti Soekmono ${ }^{\varpi_{1}}$, Dhita Paranita Ningtyas ${ }^{2}$ \\ Pendidikan Guru Pendidikan Anak Usia Dini, Universitas Trilogi \\ DOI: $10.31004 /$ obsesi.v4i2.444
}

\begin{abstract}
Abstrak
Pendidikan multikultural sangat efektif diberikan pada anak usia dini karena kesadaran tentang keberagaman sebagai dasar sikap toleran mulai berkembang pada usia 5 tahun, sehingga guru Anak Usia Dini (AUD) memerlukan kemampuan, keterampilan dan sikap positif yang tepat untuk mengajarkan pendidikan multikultural. Penelitian ini bertujuan untuk menemukan strategi meningkatkan kemampuan mahasiswa PG-PAUD dalam membuat perencanaan dan media pembelajaran multikultural AUD. Pendekatan penelitian menggunakan Penelitian dan Pengembangan $(R$ and $D)$ yang dimodifikasi dalam tiga langkah penelitian yaitu: studi pendahuluan berisi studi pustaka materi perkuliahan, dan studi latar belakang sosial budaya mahasiswa; pengembangan model yaitu identifikasi tema multikultural sesuai latar belakang budaya mahasiswa, perencanaan dan media pembelajaran multikultural; dan tes validasi model berupa validasi kemampuan mahasiswa membuat perencanaan dan media pembelajaran multikultural. Hasilnya adalah signifikan, efektif dan layak. Temuan penelitian ini, komunikasi dan partisipasi mahasiswa dalam kelompok kolaboratif adalah faktor yang berpengaruh untuk meningkatkan kemampuan mahasiswa membuat perencanaan pembelajaran multikultural.
\end{abstract}

Kata kunci: model pembelajaran; pendidikan multikultural; kolaboratif; pembelajaran dengan pendekatan proyek

\begin{abstract}
Multicultural education is effective for early childhood, because diversity awareness is a basic step of tolerance, develop at five years old. This study is aimed to uncover learning strategy in enhancing students ability of early childhood education training programme to make learning plan and apparatus for multicultural of early childhood education. This study employs Research and Development approach modified into three phases of research: preliminary study consist of bibliographical study of course contents and culturesocial background study of student; development model consist of three steps, namely, identification of multicultural theme like culture-social background study of student, make lesson plan and apparatus of multicultural; and validation test model is comprised of validation about student ability to make lesson plan and apparatus of multicultural. The research result is significant, effective and appropriate. Discoveries resulting from study, communication and participation of students in collaborative groups are factors influencing level of student ability to make lesson plan and apparatus of multicultural.

Keywords: Model of Learning; Multicultural Education; Collaborative; and Project Approach Learning
\end{abstract}

Copyright (c) 2020 Roostrianawahti Soekmono, Dhita Paranita Ningtyas

$\triangle$ Corresponding author:

Email Address : roostri73@trilogi.ac.id (Jakarta, Indonesia)

Received 24 January 2020, Accepted 2 March 2020, Published 25 March 2020 


\section{PENDAHULUAN}

Pengembangan pendidikan multikultural di Indonesia masih menjadi wacana, termasuk di Pendidikan Anak Usia Dini (PAUD). Agar tidak sekedar menjadi wacana, guru PAUD memerlukan pengetahuan, keterampilan dan sikap positif yang tepat untuk merealisasi pendidikan multikultural di kelasnya (Berthelsen \& Karuppiah, 2011). Oleh karena itu melalui penelitian sebelumnya, peneliti mengembangkan "Model Pendidikan Multikultural melalui Program Bahasa Holistik". Hasil penelitian di TK Nasima Semarang menunjukkan peningkatan kesadaran tentang keberagaman baik pengetahuan, keterampilan dan sikap positif terhadap keberagaman suku dan budaya, misalnya anak dapat mengenal identitas sukunya dan suku temannya serta menyikapinya dengan cara positif (Soekmono, 2017). Kesadaran tentang keberagaman merupakan dasar dari sikap toleransi yang sangat diperlukan Indonesia sebagai bangsa yang multikultural.

Pentingnya bekal untuk mengajarkan pendidikan multikultural juga diteliti oleh Soyoun Bae-suh, Sophia Han, Soon Hwan Kim dalam penelitian, "Implementing Multicultural Education for Young Children in South Korea: Early Childhood Teachers' Needs". Guru memerlukan pelatihan tentang perencanaan, integrasi dan implementasi kurikulum untuk anak dari keluarga multikultur agar bisa mengajarkan pendidikan multikultural untuk anak usia dini (Bae-suh, Han, 2015). Brigiite Vittrup (2016) juga menguatkan dalam penelitiannya tentang "Early Childhood Teachers' Approaches to Multicultural Education and Perceived Barriers to Disseminating Anti Bias Message". Guru perlu mengetahui isu multikultural agar guru dapat membimbing anak berinteraksi dengan anak dari suku/etnik yang berbeda dengan dirinya, karena Anak mulai menemukan ide tentang ras dan atributnya, serta ekspresi bias pada usia 3-5 tahun. Penelitian ini menggunakan pendekatan Bank dan menggunakan Colormute approaches (Vittrup, 2016).

Mengingat bekal pengetahuan, keterampilan dan sikap terhadap keberagaman dengan cara positif untuk mengajarkan Pendidikan multikultural yang diperlukan calon guru PAUD belum dikembangkan prodi PG-PAUD lain, maka peneliti tertarik melakukan penelitian R and D “Model Pembelajaran Pendidikan Multikultural melalui Pendekatan Proyek Kolaboratif" pada mata kuliah "Pengembangan Model Pendidikan Multikultural AUD". Penelitian ini dilakukan pada prodi PG-PAUD Universitas Trilogi karena saat ini Universitas Trilogi sudah mengembangkan mata kuliah tersebut. Materi perkuliahan dikembangkan dari hasil penelitian sebelumnya yaitu "Model Pendidikan Multikultural melalui Program Bahasa Holistik". Model Pendidikan Multikultural melalui program bahasa holistik memberikan nilai yang sangat besar untuk ilmu pengetahuan dan merupakan jawaban "Janji Bali" (Bali Promise), bahwa budaya dapat mendorong, mengembangkan dan memperkaya pembangunan berkelanjutan atau suistanable development (Sartika, 2019), sehingga berharga untuk pengembangan kurikulum PAUD.

Penelitian dilakukan dengan pendekatan proyek agar ada produk yang dihasilkan melalui kelompok kolaboratif sesuai latar belakang sosial budaya mahasiswa. Sesuai penelitian Tielman, and Brok, Collaborative learning merupakan metode pembelajaran yang berbasis bekerja bersama dalam kelompok dengan berbagi tujuan pendidikan bersama, sehingga peserta didik dapat berinteraksi dan belajar dari kemampuan dan keterampilan peserta didik lain serta mendorong kolaborasi dalam kelompok (Kennedy Tielman , Perry den Brok, 2011) . Menurut Baker and Clark (2010), collaborative learning cocok untuk kelas multikultural. Integrasi metode ini pada peserta didik yang beragam budaya dapat mengembangkan keberagaman budaya tetapi juga membantu untuk mengkreasi sensitivitas budaya. Guru memerlukan keterampilan pedagogis dalam kelas multikultural, pengajaran tentang pemberian tugas kolaboratif, bimbingan untuk mencapai tujuan, manfaat kolaboratif learning dalam kelas multikultural (Trish Baker, 2010).

Penelitian ini difokuskan untuk: (1) Mengidentifikasikan model yang dikembangkan oleh dosen untuk meningkatkan kemampuan mahasiswa prodi PG-PAUD membuat perencanaan dan media pembelajaran pendidikan multikultural AUD; (2) Mengidentifikasi- 
kan tingkat kemampuan mahasiswa membuat perencanaan dan media pembelajaran pendidikan multikultural AUD; (3) Menemukan cara merancang model pembelajaran pendidikan multikultural AUD melalui pendekatan pembelajaran proyek kolaboratif untuk meningkatkan kemampuan mahasiswa prodi PG-PAUD membuat perencanaan dan media pembelajaran multikultural AUD; (4) Menemukan strategi pelaksanaan model pembelajaran pendidikan multikultural AUD melalui pendekatan pembelajaran proyek kolaboratif untuk meningkatkan kemampuan mahasiswa prodi PG-PAUD membuat perencanaan dan media pembelajaran multikultural AUD; (5) Memperoleh data empiris peningkatan kemampuan mahasiswa prodi PG-PAUD membuat perencanaan dan media pembelajaran multikultural AUD setelah pelaksanaan.

Pendidikan multikultural menurut Choirul Mahfud memiliki ciri-ciri: (1) pendidikan yang dapat membentuk 'manusia budaya' dan menciptakan 'masyarakat berbudaya (berperadaban)'. (2) materi pendidikan multikultural dapat mengajarkan nilai-nilai luhur kemanusiaan, nilai-nilai bangsa, dan nilai-nilai kelompok etnis atau kultur, (3) metode Pendidikan multikultural demokratis, menghargai aspek-aspek perbedaan keberagaman budaya bangsa dan kelompok etnis (multikulturalis), (4) evaluasi terhadap tingkah laku anak didik yang meliputi persepsi, apresiasi, dan tindakan budaya lainnya (Mahfud, 2013). Strategi penyampaian Pendidikan Multikultural diuraikan Banks melalui empat dasar pendekatan pendidikan multikultural, yaitu: (1) The Contributions Approach, (2) The Additional Approach, (3) The Transformation Approach, (4) The Social Action Approach (Banks, 2015). Pelaksanaan pendidikan multikultural dilakukan dengan integrasi budaya dalam perencanaan pembelajarannya, dimana tema Budaya dalam perencanaan pembelajaran digali secara mendalam, tidak terburu-buru agar tidak menjadi pendekatan turis (DermanSparks \& Force, 2010). Menurut Mahmud dan Alim, pembelajaran multikultural sangat diperlukan di daerah pesisir, karena keberagaman di wilayah pesisir membutuhkan suatu model pembelajaran yang dapat memperekat perbedaan (Machmud \& Alim, 2018). Peningkatan pemahaman anak tentang keberagaman dapat menggunakan buku cerita popup berbasis pendidikan multikultural (Kusumaningrum \& Wahyono, 2019).

Perencanaan pembelajaran tematik berisi daftar kegiatan, tujuan pengalaman belajar untuk anak, metode pembelajaran, tanggungjawab guru, baik berupa perencanaan harian, mingguan, bulanan atau tema spesifik (Gordon, 2014). Model webbed atau yang kita kenal dengan tematik dapat digunakan guru untuk mengembangkan perencanaan pembelajaran anak usia dini dengan pendekatan proyek (Arthur, Beecher, Death, Farmer, \& Dockett, 2014). Peneliti menggunakan perencanaan pembelajaran tematik karena guru PAUD sebagian besar sudah memahami perencanaan pembelajaran tersebut(Apriyanti, 2017).

Pengembangan media pembelajaran Pendidikan multikultural melalui proses analisis kebutuhan berupa identifikasi kebutuhan media pembelajaran menggunakan observasi dan wawancara, disesuaikan tema, kebutuhan dan kemampuan anak didik serta tujuan yang ingin dicapai (Mursid, 2016). Selanjutnya adalah pemetaan media pembelajaran meliputi: kebutuhan media pembelajaran dan mengetahui urutan media pembelajaran untuk menentukan prioritas, untuk media pembelajaran multikultural sangat memperhatikan ketentuan kesesuaian dengan tahapan perkembangan anak dan tidak ada rasis (Sigit Purnama, Yuli Salis Hijriani, 2019). Struktur media pembelajaran disesuaikan taksonomi media. Setelah dipetakan selanjutnya dilakukan penyusunan media untuk mengetahui relevansi atau keterkaitan, konsistensi dan kecukupan (Sukiman, 2012). Media pembelajaran multikultural selanjunya dievaluasi efektivitasnya kemudian direvisi (Sigit Purnama, Yuli Salis Hijriani, 2019).

Pendekatan proyek berisi tema yang dieksplorasi pada periode tertentu harian atau mingguan. Guru dapat mengamati, menanyakan, memperkirakan, percobaan dan penelitian yang terkait tema (Gordon, 2014). Gray mendefinisikan pendekatan Pembelajaran Proyek berupa studi terus menerus dari topik setiap hari secara mendalam untuk memahami dan diperluas dengan sub topik yang relevan. Bimbingan untuk mahasiswa terdiri dari tiga 
proses fase: Fase 1: Mahasiswa membangun minat pada topik melalui berbagi cerita pengalaman pribadi yang relevan dengan topik. Mereka merepresentasikan pemahaman spesifik mereka terhadap topik dan mahasiswa dapat menilainya. Fase 2: Mahasiswa belajar tentang topik, mereka pergi ke lapangan melalui kunjungan dan wawancara langsung, melihat-lihat buku, situs internet, video, dan lainnya. Mereka menggunakan berbagai bentuk representasi untuk menggambarkan apa yang mereka pelajari dan berbagi pengetahuan baru. Dan Fase 3: Terakhir, mahasiswa dibimbing untuk membuat kesimpulan dari studi dan penilaian guru-guru (Gray, Erika; Minasian, Julie; Piñon, 2009).

\section{METODOLOGI}

Pendekatan dan Metode penelitian yang dipilih untuk penelitian ini adalah Penelitian dan Pengembangan yang menggunakan prosedur dan langkah-langkah penelitian Borg and Gall yang mengadaptasi desain Instruksional Dick and Carey. Strategi penelitian terbagi menjadi tiga uji coba, dalam penelitian ini tidak dilakukan uji coba satu kelas (uji coba produk) dan tidak dilakukan uji sumatif, uji yang dilakukan adalah uji coba prototipe satu satu, satu evaluator mengevaluasi satu orang dan uji coba kelompok kecil dengan enam s.d. delapan orang atau uji formatif (Borg, R. Walter, Meredith Gall, 2007).

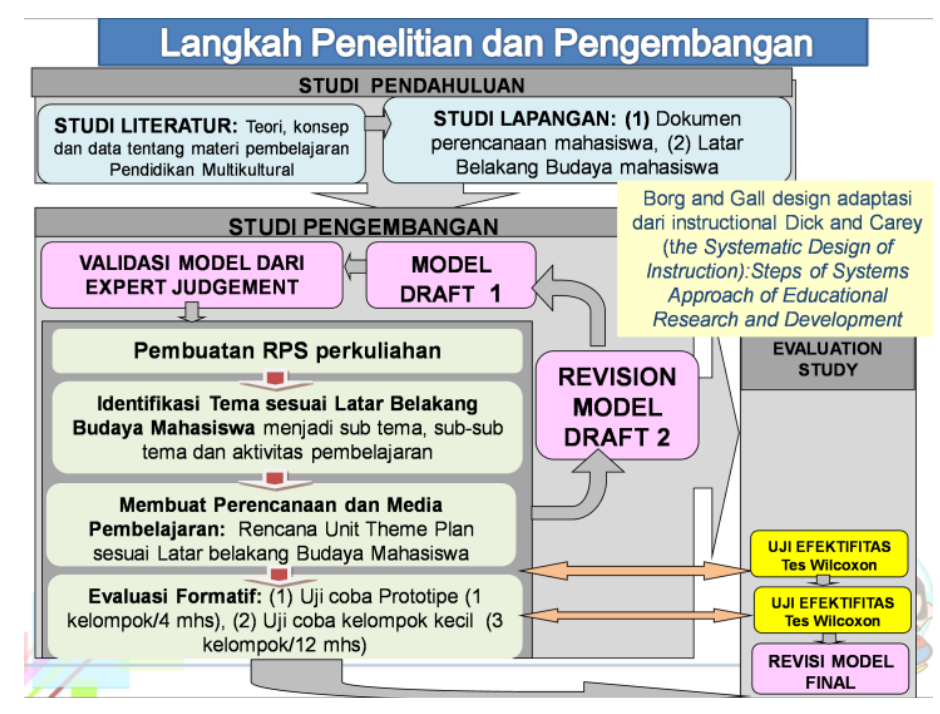

Gambar 1. Langkah-langkah penelitian dan pengembangan model

Tempat penelitian dilakukan di kota Jakarta dengan pertimbangan penduduknya sangat beragam (multikultural). Uji coba dilakukan di satu Prodi PG-PAUD dengan pertimbangan: (1) PG-PAUD Universitas Trilogi memiliki mahasiswa yang beragaman suku (lebih dari empat suku); (2) PG-PAUD Universitas Trilogi memiliki mata kuliah Pengembangan Pendidikan Multikultural AUD. Waktu Penelitian dilakukan pada tahun 2018.

Teknik analisis data yang digunakan dalam penelitian ini menggunakan pendekatan kualitatif Inkuiri Naturalistik untuk data kualitatif, sedangkan untuk data kuantitatif berupa data kategorisasi dianalisis dengan uji Wilcoxon. Analisis data kualitatif dengan inkuiri Naturalistik dilakukan untuk mendapatkan temuan-temuan yang dapat digunakan untuk perbaikan model. Sedangkan analisis data kuantitatif dengan Uji Wilcoxon yang merupakan uji non parametrik untuk data kategorisasi dari data berpasangan (misal: pre-test dan posttest) yang diberi peringkat (Wibisono, 2009). Data post test dan pretest di tabulasi selisihnya kemudian diberi peringkat $(\mathrm{T})$. Hasil tabulasi peringkat $(\mathrm{T})$ setiap indikator penilaian dicari nilai p-nya untuk menentukan apakah signifikan atau tidak. 
Rancangan Model Draf 1a "Model Pembelajaran Pendidikan Multikultural AUD melalui Pendekatan Proyek" terdiri dari model konseptual, dan model prosedural. Berikut ini adalah modelnya:
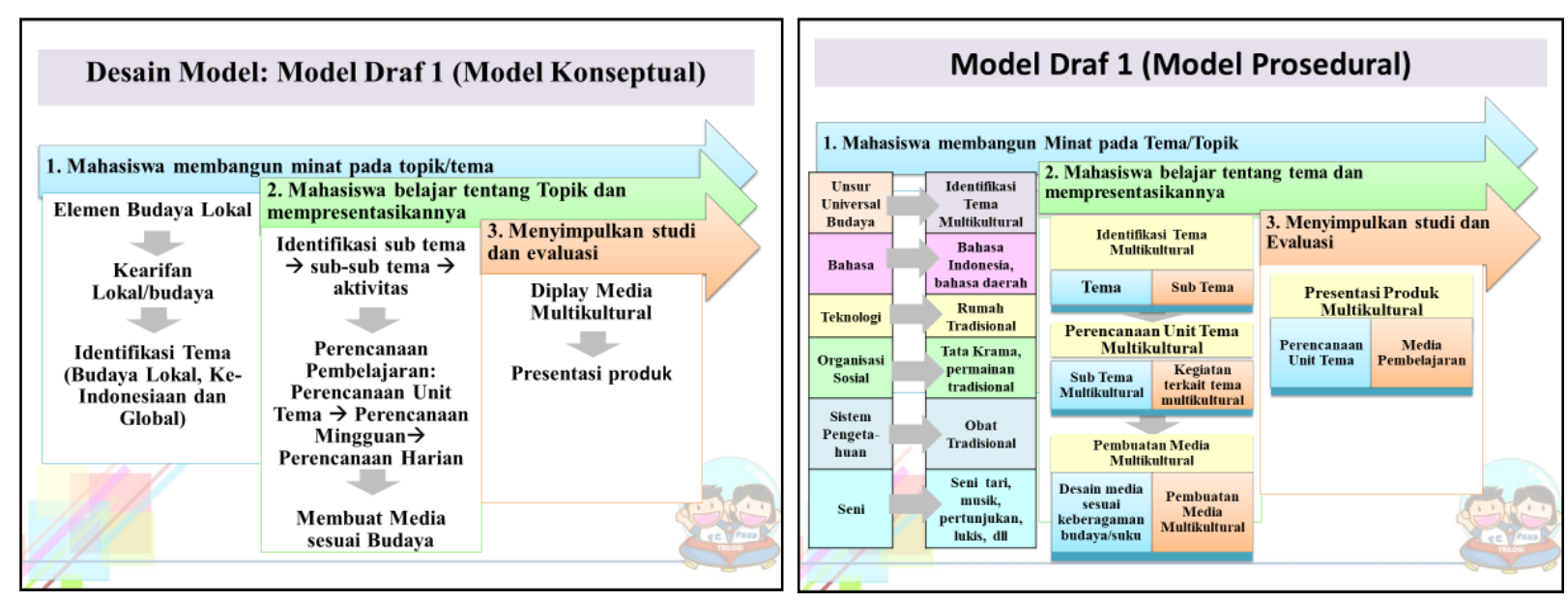

Gambar 2. Model Draf 1 untuk Model Konseptual dan Prosedural

\section{HASIL DAN PEMBAHASAN}

Pada studi pendahuluan dilakukan Studi Pustaka untuk membuat materi perkuliahan Pendidikan Multikultural, susunan materinya tertuang dalam Rencana Pembelajaran Semester (RPS) Pengembangan Pendidikan Multikultural untuk Anak Usia Dini. Media-media penunjang berupa alat permainan pendidikan multikultural yang digunakan untuk proses perkuliahan diantaranya adalah Alat Permainan Edukatif (APE) multikultural seperti boneka suku, buku cerita multikultural, keping geometri, puzzle, dan maze rumah tradisional dan bangunan di kota lama yang merupakan bentuk media keberagaman budaya.

Studi Lapangan Latar Belakang Sosial dan Budaya Mahasiswa berupa penyebaran kuesioner dilakukan satu kali pada mahasiswa program studi PG-PAUD angkatan pertama yaitu angkatan 2016/2017, dari 12 kuesioner yang disebar semua kuesioner kembali, sehingga terkumpul 12 responden. Berdasarkan hasil kuesioner yang telah diisi oleh responden maka yang sesuai dengan kriteria pemilihan sampel mahasiswa untuk uji prototipe dan uji kelompok kecil diperoleh data yang ditampilkan dalam diagram lingkaran.

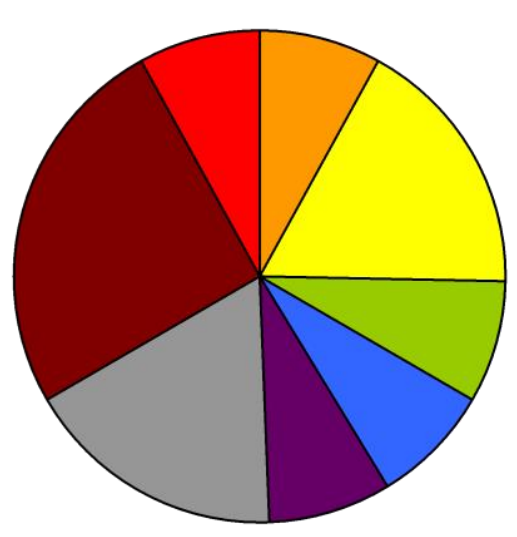

$\square$ Ambon-Belanda-Betawi-India-Minang
$\square$ Ambon-Sunda Jawa
$\square$ Arab-Minang-Melayu
$\square$ Jawa-Minang
$\square$ Sunda Betawi
$\square$ Minang
$\square$ Jawa
$\square$ Betawi

Gambar 3. Grafik Keberagaman Suku Mahasiswa Prodi PG-PAUD Univ. Trilogi 
Berdasarkan data keberagaman suku ditemukan bahwa mahasiswa prodi PG-PAUD Universitas Trilogi merupakan kelompok yang beragam sukunya karena terdiri dari lebih 4 suku. Penelitian ini menggunakan pendekatan proyek sehingga mahasiswa tersebut dibagi menjadi 3 kelompok sesuai latar belakang sukunya. Kelompok 1 Budaya di Maluku (anggota: mahasiswa dari suku Ambon-Belanda-Betawi-India-Minang dan suku AmbonSunda-Jawa) untuk uji coba Prototipe karena paling beragam. Sedangkan kelompok 2 Budaya di Sumatera Barat (anggota: mahasiswa dari suku Arab-Minang-Melayu, suku JawaMinang dan suku Minang), dan kelompok 3 Budaya di Jawa (anggota: mahasiswa dari suku Sunda-Betawi, suku Jawa dan suku Betawi) untuk uji coba kelompok kecil.

Instrumen review portofolio hasil perencanaan dan media yang dibuat oleh mahasiswa dalam proyek kolaboratif dibuat dan divalidasi oleh expert judgement. Pada uji coba prototipe kelompok 1 mengembangkan perencanaan dan media pembelajaran pendidikan multikultural AUD dari tema "Gemulai Tarian Lenso dari Ambon" yang berasal dari Ambon (budaya lokal). Pengembangan perencanaan tidak hanya budaya lokal (tari lenso) tapi juga "Tari Lenso" (Minahasa), "Tari Saputangan" (Sumatera Utara), "Tari Saputangan Bapuncu Ampat" (Kalimantan) yang merupakan budaya nasional serta Tari Lenso Portugis (Budaya Global).

Hasil identifikasi tema multikultural menjadi sub tema multikultural dan perencanaan unit tema multikultural pada uji coba prototipe tema multikultural "Gemulai Tarian Lenso Ambon" dari kelompok 1 dianalisis dengan analisis domein, domein pertama "X adalah termasuk $Y$ " dan domein kedua " $X$ adalah langkah-langkah dalam $Y$ ". Hasil analisis domein menunjukkan bahwa perencanaan unit tema multikultural masih memerlukan revisi. Pertama, Identifikasi sub tema menggunakan 5W1H masih lebih banyak mengangkat budaya lokal, hanya sedikit di budaya Nasional dan global. Kedua, Perencanaan unit tema multikultural masih ditemui kesalahan-kesalahan yang perlu direvisi diantaranya: (a) semua kegiatan teridentifikasi sebagai kegiatan budaya lokal; (b) satu kegiatan terkait dengan kearifan lokal; (c) ada 2 kegiatan di sentra persiapan yang lebih cocok masuk ke sentra bahasa dan sentra seni; (d) kegiatan di sentra ibadah tidak terkait dengan tema multikultural; (e) tidak ada kegiatan di sentra sain.

Berdasarkan analisis domein, ditemukan bahwa mahasiswa masih melakukan kesalahan pembuatan perencanaan pembelajaran pendidikan multikultural sehingga dilakukan revisi draf 1 untuk model konseptual menjadi draf 2 untuk model konseptual. Revisi dilakukan pada langkah 1 dan langkah 2, berikut ini adalah model konseptual draf 2:

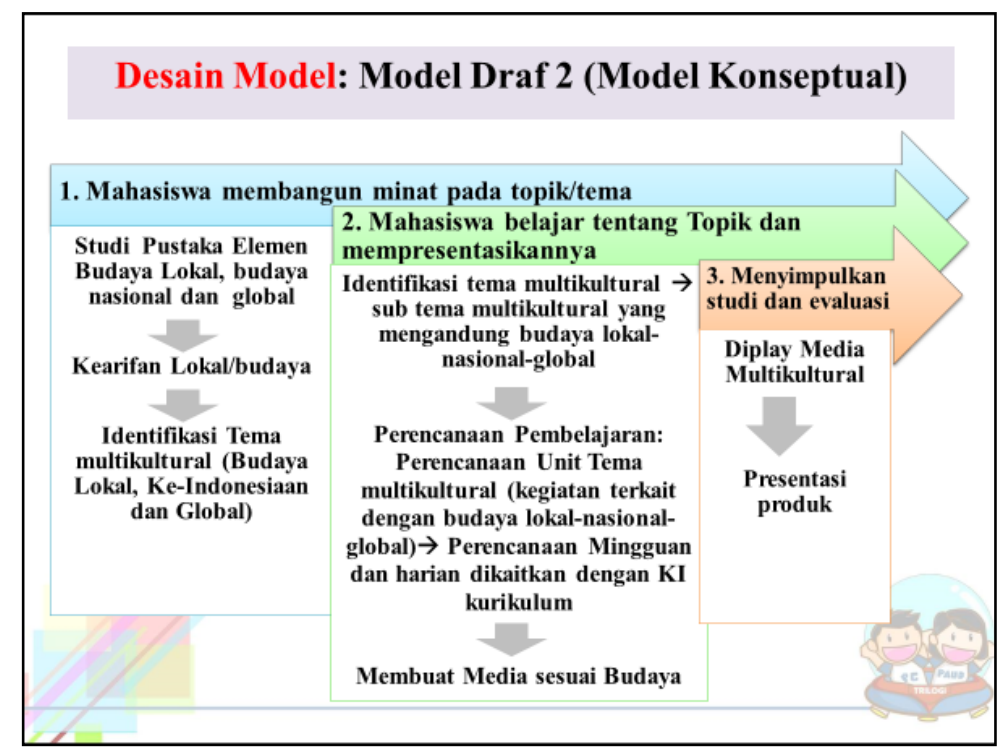

Gambar 4. Desain Model Draf 2 untuk Model Konseptual 
Tema yang dikembangkan kelompok 2 (Uji coba Kelompok Kecil) adalah: "Rumah Adat Sumatera Barat" rumah suku Minang dari Sumatera Barat (budaya lokal) ada beberapa jenis rumah gadang di Sumatera Barat seperti rumah gadang atap stasiun, rumah gadang atap tungkuih nasi (budaya Nasional), "Rumah Melayu" rumah suku melayu dari Sumatera Barat, yang merupakan global adalah rumah suku Melayu di pesisir selatan Sumatera Barat sejenis dengan rumah Melayu di negeri Sembilan Malaysia (Budaya Global). Tema yang dikembangkan kelompok 3 (Uji coba Kelompok Kecil) adalah: "Indahnya Keberagaman Kebaya di Jawa" (budaya lokal dan budaya Nasional). Di setiap negara juga memiliki pakaian tradisional (budaya global). Berikut ini adalah Identifikasi Tema Kelompok 3 dalam Uji Coba Kelompok Kecil.

Evaluasi model dilakukan berdasarkan evaluasi dosen terhadap portofolio tugas mahasiswa secara kelompok menggunakan form review portofolio. Setelah itu dianalisis dengan analisis domein catatan lapangan/perencanaan pembelajaran pendidikan multikultural, analisis taksonomi dari pengamatan terfokus, analisis komponen dari pengamatan terpilih melalui pertanyaan diadik dan triadik. Hasil analisis domein menunjukkan bahwa perencanaan unit tema multikultural masih memerlukan revisi, yaitu: identifikasi sub tema menggunakan $5 \mathrm{~W} 1 \mathrm{H}$ masih lebih banyak mengangkat budaya lokal dan nasional, belum terlihat budaya global. Sebenarnya dalam draft model sudah ada identifikasi untuk budaya global sehingga dari analisis domein tidak perlu revisi untuk model konseptual mahasiswa hanya masih memerlukan lebih banyak latihan dalam membuat perencanaan pembelajaran pendidikan multikultural. Hasil analisis taksonomi uji coba kelompok kecil berupa daftar tingkatan tentatif dengan istilah peneliti dan daftar taksonomi lengkap. Analisis taksonomi lengkap dapat digunakan untuk mengidentifikasi kegiatan-kegiatan di perencanaan unit tema multikukultural yang belum diidentifikasikan oleh mahasiswa selanjutnya dilakukan analisis komponen dan analisis tema. Tema yang ditemukan dari analisis tema adalah apa saja kegiatan yang "termasuk kegiatan di sentra yang terkait dengan budaya lokal, nasional dan global" yang dapat digunakan untuk meningkatkan kemampuan mahasiswa membuat perencanaan unit tema multikultural khususnya "Pemahaman keterkaitan kegiatan dengan Tema Multikultural (budaya lokal, nasional dan global)". Selain itu temuan tersebut dapat dimanfaatkan untuk revisi model draf 2 menjadi model final dari model prosedural.
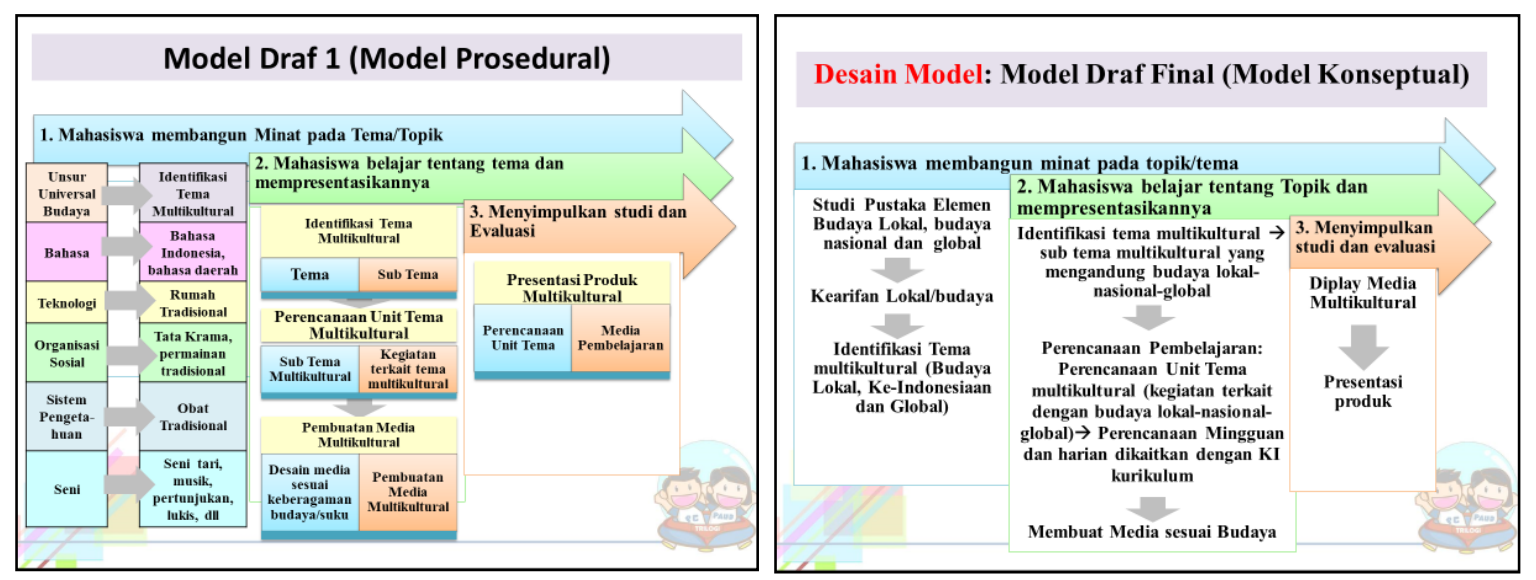

Gambar 5. Desain Model Final untuk Model Konseptual dan Prosedural

Model fisikal final berupa Buku Pendidikan Multikultural untuk Anak Usia Dini yang isinya dikembangkan dari Disertasi peneliti yaitu "Model Pendidikan Multikultural melalui Program Bahasa Holistik", dan materi pembelajaran mata kuliah "Pengembangan Pendidikan Multikultural untuk Anak Usia Dini" yang di kembangkan dengan "Model Pembelajaran Pendidikan Multikultural untuk Anak Usia Dini melalui Pendekatan Pembelajaran Proyek Kolaboratif". 
Sebelum uji efektifitas, data hasil perencanaan pembelajaran pendidikan multikultural dan pembuatan media pembelajaran pendidikan multikultural di rekapitulasi di review portofolio. Portofolio perencanaan pembelajaran dan media pembelajaran pendidikan multikultural dikategorisasikan menjadi empat tahapan yaitu tahap 1 Mengenal tema multikultural, identifikasi tema multikultural dan perencanaan pembelajaran pendidikan multikultural dengan bimbingan dosen, tahap 2 Eksplorasi tema multikultural, identifikasi tema multikultural dan perencanaan pembelajaran pendidikan multikultural dengan sedikit bimbingan dosen, tahap 3 Mengidentifikasikan tema multikultural, identifikasi tema multikultural dan perencanaan pembelajaran pendidikan multikultural dengan motivasi dosen, tahap 4 Mendiskusikan tema multikultural, identifikasi tema multikultural dan perencanaan pembelajaran pendidikan multikultural tanpa bimbingan dan motivasi dosen.

Tahapan tersebut merupakan konstruk konsep penyusunan perencanaan pembelajaran pendidikan multikultural (Content Validity) yang berlaku untuk empat kelompok indikator asesmen yaitu (1) pemahaman keterkaitan sub tema dan kegiatan dengan tema multikultural (empat item); (2) keterampilan membuat identifikasi tema multikultural menjadi sub tema multikultural (tiga item); (3) keterampilan membuat perencanaan unit tema multikultural (tiga item); (4) keterampilan mengembangkan media pembelajaran pendidikan multikultural (tiga item). Dari 13 item indikator tahapan yang muncul pertama merupakan pre-test dan yang muncul terakhir merupakan post-test. Berikut adalah rekapitulasi kemampuan mahasiswa membuat perencanaan dan media pendidikan multikultural pada uji coba prototipe yang merupakan rekapitulasi data review portofolio.

Efektifitas model diuji melalui uji Wilcoxon dan uji ini hanya dilakukan untuk indikator asesmen yang ada peningkatan tahapan, sedangkan untuk indikator yang tidak ada peningkatan tidak dilakukan uji Wilcoxon (T). Selain itu uji ini hanya dilakukan pada uji coba kelompok kecil (sembilan mahasiswa), tetapi tidak dilakukan pada uji coba prototipe (tiga mahasiswa). Uji coba kelompok kecil dilakukan pada 9 mahasiswa yaitu Marini, Rika, Masta, Oktariani, Nur, Alifah, Sri, Devitha dan Sarah, analisis data menggunakan pre-test dan post-test one group design.

Tabel 1. Uji Signifikansi indikator asesmen indikator penilaian pada Uji Coba Kelompok Kecil

\begin{tabular}{lcccc}
\hline Indikator Penilaian & $\begin{array}{c}\text { Jumlah Sampel } \\
(\mathbf{n})\end{array}$ & $\begin{array}{c}\text { Nilai Statistik } \\
\text { Wilcoxon (T) }\end{array}$ & Nilai-p & Keputusan \\
\hline $\begin{array}{l}\text { Sub tema dan kegiatan terkait } \\
\text { budaya lokal }\end{array}$ & 9 & 15 & 0,03 & Signifikan \\
$\begin{array}{l}\text { Sub tema dan kegiatan terkait } \\
\text { budaya nasional }\end{array}$ & 9 & 9 & 0,06 & Signifikan \\
$\begin{array}{l}\text { Identifikasi tema menjadi sub } \\
\text { tema }\end{array}$ & 9 & 9 & 0,06 & Signifikan \\
$\begin{array}{l}\text { Identifikasi tema dan kegiatan } \\
\begin{array}{l}\text { Pemilihan kegiatan sesuai } \\
\text { kurikulum }\end{array}\end{array}$ & 9 & 15 & 0,03 & Signifikan \\
\hline
\end{tabular}

Kesimpulannya pengembangan model pendidikan multikultural mempunyai pengaruh pada taraf signifikansi 0,03 pada indikator penilain/asesmen "Sub tema dan kegiatan terkait budaya lokal" dan "Identifikasi tema dan kegiatan", serta taraf signifikansi 0,06 pada indikator "Sub tema dan kegiatan terkait budaya nasional", "Identifikasi tema menjadi sub tema" dan "Pemilihan kegiatan sesuai kurikulum".

Peneliti menfokuskan asesmen pada pembuatan perencanaan pembelajaran pendidikan multikultural, maka pada uji coba kelompok kecil peneliti hanya melakukan fokus pada satu domein. Peneliti pada pengamatan terfokus (catatan lapangan uji coba 
kelompok kecil) hanya mengamati satu domein yaitu hubungan semantik adalah termasuk melakukan peningkatan pemahaman sub tema dan kegiatan yang terkait budaya lokal dan pemahaman sub tema dan kegiatan yang terkait dengan budaya Nasional, keterampilan mengidentifikasikan tema menjadi sub tema, keterampilan identifikasi tema dan kegiatan serta keterampilan pemilihan kegiatan sesuai kurikulum.

Harapannya temuan observasi yang lebih mendalam dapat menemukan "meningkatkan kemampuan dan keterampilan mahasiswa membuat perencanaan pembelajaran pendidikan multikultural untuk AUD dalam pelaksanaan model pembelajaran pendidikan multikultural melalui pendekatan proyek kolaboratif". Dari hasil uji kelompok kecil ternyata pada taraf signifikan 0,03 dan 0,06 semua signifikan dan setelah dilakukan observasi lebih tekun pada pengamatan terfokus ditemukan: (a) Indikator tambahan pengelompokan kegiatan pada perencanaan pembelajaran "yang termasuk" kegiatan di sentra persiapan bahasa, sentra persiapan matematika, sentra seni, sentra bahan alam, sentra bermain peran dan sentra balok. (b) dosen pada uji coba kelompok kecil lebih fokus menggali kemampuan dan keterampilan mahasiswa identifikasi sub tema menjadi kegiatan yang sesuai dengan budaya lokal, nasional dan global di setiap sentra pembelajaran, sehingga indikator tersebut lebih sering muncul dibandingkan pada saat uji prototipe. Observasi lebih tekun dilakukan tidak hanya melalui hasil perencanaan pembelajaran yang disusun mahasiswa, peneliti membandingkan dan melakukan observasi dari sumber lain seperti media pembelajaran pendidikan multikultural yang dibuat mahasiswa. Semua ini dilakukan untuk memperoleh data yang dapat dipercaya dan tidak bias, dengan harapan dapat diperoleh model final yang derajat kredibilitasnya tinggi.

Mata kuliah Pengembangan Pendidikan multikultural untuk Anak Usia Dini merupakan mata kuliah pengembangan yang dijadikan salah satu unggulan Prodi PGPAUD Universitas Trilogi. Mata kuliah ini belum dikembangkan oleh prodi sejenis di Indonesia. Model Pembelajaran Pendidikan Multikultural melalui Pendekatan Proyek Kolaboratif untuk meningkatkan kemampuan dan keterampilan mahasiswa membuat perencanaan dan media pembelajaran pendidikan multikulturak AUD dikembangkan menggunakan desain pengembangan model Borg and Gall yang mengadaptasi desain instruksional Dick and Carey dengan menyebutnya sebagai Steps of Systems Approach of Education Research and Development. Model draft 1 tersebut sudah dikembangkan berdasarkan konsep-konsep kemudian divalidasi oleh pakar.

Instrumen untuk menilai portofolio perencanaan pembelajaran pendidikan multikultural untuk AUD dievaluasi pakar. Setelah evaluasi pakar, instrumen tersebut digunakan untuk evaluasi perencanaan pembelajaran yang sudah dibuat mahasiswa pada uji coba prototipe. Perencanaa yang dibuat mahasiswa disesuaikan dengan latar belakang sosial budayanya dan materinya diperoleh dari telaah pustaka. Berdasarkan telaah pustaka dan evaluasi pembuatan perencanaan model draft 1 direvisi menjadi model draft 2 .

Model draft 2 selanjutnya diuji coba lagi dalam kelompok kecil (sampel 9 mahasiswa), direvisi berdasarkan hasil studi pustaka dan evaluasi perencanaan pembelajaran pendidikan mutikultural AUD yang dibuat mahasiswa pada uji coba kelompok kecil. Data hasil uji coba dianalisis dengan analisis domein-analisis taksonomianalisis komponen-analisis tema sehingga model direvisi menjadi model final. Analisis data kualitatif dengan pendekatan inkuiri naturalistik model spradley dilakukan peneliti untuk menemukan kegiatan yang termasuk kegiatan dalam sentra persiapan bahasa, persiapan matematika, bahan alam, seni, bermain peran dan balok yang terkait dengan budaya lokal, nasional dan global (multikultural) karena model ini baru. Hasil temuan kegiatan yang termasuk kegiatan dalam sentra persiapan bahasa, persiapan matematika, bahan alam, seni, bermain peran dan balok yang terkait dengan budaya lokal, nasional dan global (multikultural) dapat memudahkan peneliti untuk memperbaiki model. Penggunaan metode pengumpulan data kualitatif dan tehnik analisis data kualitatif dikembangkan Dick and 
Carey dalam evaluasi formatif, menurutnya selain menggunakan metode kualitatif, metode kuantitatif juga digunakan berupa tes performan (Borg and Gall, 2007:591).

Selanjutnya data kuantitatif berupa tahapan kemampuan dan keterampilan mahasiswa membuat perencanaan pembelajaran pendidikan multikultural untuk AUD yang diperoleh dari review portofolio perencanaan pembelajaran digunakan untuk uji efektivitas model. Dari uji coba model draft 2 melalui uji coba kelompok kecil disimpulkan bahwa model draft 2 mempunyai pengaruh pada taraf signifikansi 0,03 dan 0,06. Berdasarkan uji coba prototipe, uji coba kelompok kecil dan uji efektifitas model pembelajaran pendidikan multikultural melalui pendekatan proyek kolaboratif diharapkan diperoleh model final yang sudah teruji.

Faktor pendukung dalam pengembangan dan implementasi model adalah: (1) pengembangan model draf 1 disusun berdasarkan konsep-konsep yang relevan dengan pendidikan multikultural dan pendekatan pembelajaran proyek (project approach), (2) instrumen dievaluasi oleh pakar berdasarkan teori dan konsep multikultural Indonesia, (3) implementasi model didukung oleh mahasiswa yang benar-benar berusaha membuat perencanaan dan media pembelajaran pendidikan multikultural, melakukan materi-materi perkuliahan dan diskusi dengan peneliti, memberikan ide dan saran perbaikan.

Selain faktor pendukung, dalam penelitian juga ditemui faktor-faktor penghambat, diantaranya adalah: (1) Konsep pendidikan multikultural untuk anak usia dini dengan latar barat, untuk Indonesia masih sangat terbatas referensinya. (3) Penelitian pendidikan multikultural sangat luas dan harus mempertimbangkan latar belakang sosial budaya, sehingga penelitian ini hanya membatasi pada satu angkatan dengan terlebih dahulu mempelajari latar belakang sosial budaya mahasiswa atau keluarga, sekolah dan mayarakat.

Model Pembelajaran Pendidikan Multikultural melalui Pendekatan Proyek Kolaboratif merupakan model awal pembelajaran pendidikan multikultural untuk anak usia dini di Prodi PG-PAUD, produk penelitian diantaranya adalah: (1) Model konseptual dan model prosedural pembelajaran pendidikan multikultural untuk AUD melalui Pendekatan Proyek Kolaboratif, (2) Model Fisik: Perencanaan dan media pembelajaran pendidikan multikultural (3) tema multikultural, Materi perkuliahan, dan buku Pengembangan Pendidikan Multikultural untuk AUD, sehingga peneliti berharap model ini dapat ditransfer di prodi lain.

Di akhir pembahasan peneliti akan mendeskripsikan tahapan perkembangan kemampuan dan keterampilan mahasiswa membuat perencanaan pembelajaran pendidikan multikultural dari sampel 1 kelompok ( 3 mahasiswa) dalam uji coba prototipe dan 2 kelompok (9 mahasiswa) dalam uji coba kelompok kecil. Pembahasan hanya difokuskan pada kemampuan yang mengalami perubahan. Berikut adalah rekapitulasi perkembangan kemampuan dan keterampilan mahasiswa membuat perencanaan pembelajaran pendidikan multikultural.

Pemahaman keterkaitan sub tema dan kegiatan dengan tema multikultural, pada kelompok 1 (uji coba prototipe) perkembangan terlihat pada dua indikator asesmen yaitu sub tema dan kegiatan yang terkait dengan budaya lokal serta sub tema dan kegiatan yang terkait budaya nasional. Kelompok 1 memiliki kemampuan sedang untuk menentukan sub tema dan kegiatan yang terkait dengan budaya lokal serta budaya nasional, artinya mereka masih memerlukan bimbingan dan motivasi dalam mengkaitkan sub tema dan kegiatan dengan budaya lokal maupun nasional. Kelompok satu (uji coba prototype) memiliki keterampilan baik dalam keterampilan membuat identifikasi tema multikultural menjadi sub tema multikultural terutama untuk indikator asesmen identifikasi tema multikultural menjadi sub tema multikultural yang mengandung budaya lokal, nasional dan global. Artinya kelompok satu masih memerlukan sedikit motivasi dalam mengidentifikasi tema multikultural menjadi sub tema multikultural yang mengandung budaya lokal, nasional dan global. Mereka sejak awal sepakat memilih tema multikultural yang terkait dengan tari Lenso yang sesuai dengan latar belakang sosial budayanya yang berasal dari Maluku, Regi 
campuran dari suku Ambon-Belanda-Betawi-Minang-Jawa, Aulia dan Rosa campuran dari suku Ambon-Sunda-Jawa.

Pemahaman keterkaitan sub tema dan kegiatan dengan tema multikultural, pada kelompok 2 dan 3 (uji coba kelompok kecil) perkembangan terlihat pada dua indikator asesmen yaitu sub tema dan kegiatan yang terkait dengan budaya lokal serta sub tema dan kegiatan yang terkait budaya nasional. Kelompok 2 dan 3 memiliki kemampuan sangat baik untuk menentukan sub tema dan kegiatan yang terkait dengan budaya lokal, artinya mereka tidak lagi memerlukan bimbingan dan motivasi dalam mengkaitkan sub tema dan kegiatan dengan budaya lokal. Kelompok 2 dan 3 memiliki kemampuan baik untuk menentukan sub tema dan kegiatan yang terkait dengan budaya nasional, artinya mereka masih memerlukan motivasi dalam mengkaitkan sub tema dan kegiatan dengan budaya nasional.

Kelompok 2 dan 3 (uji coba kelompok kecil) memiliki keterampilan baik dalam keterampilan membuat identifikasi tema multikultural menjadi sub tema multikultural terutama untuk indikator asesmen identifikasi tema multikultural menjadi sub tema multikultural yang mengandung budaya lokal, nasional dan global. Artinya kelompok 2 dan 3 masih memerlukan sedikit motivasi dalam mengidentifikasi tema multikultural menjadi sub tema multikultural yang mengandung budaya lokal, nasional dan global. Mereka sejak awal sepakat memilih tema multikultural yang terkait dengan rumah adat Sumatera Barat yang sesuai dengan latar belakang sosial budaya kelompok 2 yang berasal dari Sumatera Barat, Rika dari suku Arab-Minang-Melayu, Marini dari suku Minang-Jawa, Masta dari suku Minang dan Oktarina dari suku Pilliang (sub suku Minang). Kelompok 3 memilih tema multikultural "Indahnya keberagaman Kebaya di Pulau Jawa", karena mereka memiliki latar belakang sosial budaya dari wilayah Jawa, Sarah dari suku Betawi, Devitha dari suku Sunda-Betawi, Nur, Alifa dan Sri dari suku Jawa. Kelompok 2 dan 3 (uji coba kelompok kecil) memiliki keterampilan sangat baik dalam keterampilan membuat perencanaan pembelajaran pendidikan multikultural terutama untuk indikator asesmen identifikasi sub tema multikultural menjadi kegiatan. Artinya kelompok 2 dan 3 sudah tidak memerlukan bimbingan dan motivasi dalam mengidentifikasi sub tema menjadi kegiatan. Kelompok 2 (uji coba kelompok kecil) memiliki keterampilan baik dalam keterampilan membuat perencanaan pembelajaran pendidikan multikultural terutama untuk indikator asesmen pemilihan kegiatan sesuai dengan kurikulum, artinya kelompok 2 masih memerlukan motivasi dalam pemilihan kegiatan sesuai dengan kurikulum. Sedangkan Kelompok 3 (uji coba kelompok kecil) memiliki keterampilan sangat baik dalam keterampilan membuat perencanaan pembelajaran pendidikan multikultural terutama untuk indikator asesmen pemilihan kegiatan sesuai dengan kurikulum, artinya kelompok 3 sudah tidak memerlukan bimbingan dan motivasi dalam pemilihan kegiatan sesuai dengan kurikulum.

\section{SIMPULAN}

Model pembelajaran pendidikan multikultural melalui pendekatan proyek kolaboratif dapat dikembangkan dan diterapkan sehingga kemampuan mahasiswa meningkat sangat baik dalam pemahaman keterkaitan sub tema dan kegiatan dengan tema, keterampilan membuat identifikasi tema, terutama yang terkait dengan identifikasi menggunakan 5W1H, keterampilan membuat perencanaan dan keterampilan mengembangkan media pendidikan multikultural.

\section{UCAPAN TERIMAKASIH}

Peneliti berharap penelitian ini dapat bermanfaat dan terima kasih banyak atas dukungan pendanaan dari Hibah Dakab 2018 sehingga penelitian ini dapat terlaksana. 


\section{DAFTAR PUSTAKA}

Apriyanti, H. (2017). Pemahaman Guru Pendidikan Anak Usia Dini terhadap Perencanaan Pembelajaran Tematik. Jurnal Obsesi: Jurnal Pendidikan Anak Usia Dini, 1(2), 111. https://doi.org/10.31004/obsesi.v1i2.22.

Arthur, L., Beecher, B., Death, E., Farmer, S., \& Dockett, S. (2014). Programming and Planning: in Early Childhood Settingsss, Cengage Learning.

Banks, J. A. C. A. M. G. B. (2015). Multicultural Education: Issues and Perspectives, 9th Edition 9th Edition, Kindle Edition. In New Jersey: John Wiley and Sons.

Berthelsen, D., \& Karuppiah, N. (2011). Multicultural education: The understandings of preschool teachers in Singapore. Australian Journal of Early Childhood, 36(4), 38-42. https:// doi.org/10.1177/183693911103600406.

Borg, R. Walter, Meredith Gall, J. P. G. (2007). Education Research An Introduction (Eighth Edi). Boston: Allyn and Bacon.

Derman-Sparks, L., \& Force, A.-B. C. T. (2010). Anti-bias curriculum : tools for empowering young children. In Naeyc.

Gordon, B. (2014). Beginning and Beyond: Foundations in Early Childhood Education. International Edition (Ninth Edit). Wadsworth.

Gray, Erika; Minasian, Julie; Piñon, M. (2009). Projects of Chicagoland. Successful Implementation of the Project Approach From Early Childhood Connections Participants. Retrieved from www.kohlchildrensmuseum.org/projects.

Kennedy Tielman , Perry den Brok, S. B. \& B. V. (2011). Collaborative learning in multicultural classrooms: a case study of Dutch senior secondary vocational education. Journal of Vocational Education and Training, 64(1), 103-118. https:// doi.org/10.1080/13636820.2011.622448.

Kusumaningrum, K., \& Wahyono, S. B. (2019). Developing A Pop-Up Storybook Based on Multicultural Education for Early Childhood Students. Jurnal Obsesi : Jurnal Pendidikan Anak Usia Dini, 4(1), 41. https://doi.org/10.31004/obsesi.v4i1.230

Machmud, H., \& Alim, N. (2018). Multicultural Learning Model of PAUD in Coastal Areas. Jurnal Obsesi: Jurnal Pendidikan Anak Usia Dini, 2(2), 170. https:// doi.org/10.31004/obsesi.v2i2.74

Mahfud. (2013). Pendidikan Multikultural. Yogyakarta: Pustaka Pelajar.

Mira Sartika, SMn., M. (n.d.). Sustaining Bali Package and Bali Promise in Suatainable Development Goals. 1-16.

Mursid. (2016). Pengembangan Pembelajaran PAUD. Bandung: PT Remaja Rosdakarya.

Sigit Purnama, Yuli Salis Hijriani, H. (2019). Pengembangan Alat Permainan Edukatif Anak Usia Dini. Bandung: PT Remaja Rosdakarya.

Soekmono, R. (2017). Program Bahasa Holistik ( Penelitian Pengembangan di Kelompok B Taman Kanak-Kanak Nasima Semarang). Jurnal Pendidikan Anak Usia Dini, 11(2), 308322. https:// doi.org/10.21009/JPUD.112.09.

Soyoun Bae-suh, Sophia Han, S. H. K. (2015). Implementing Multicultural Education for Young Children in South Korea: Implementing Multicultural Education for Young Children in South Korea : Early Childhood Teachers ' Needs 1 ). International Journal of Early Childhood Special Education, 21(1, January), 95-121.

Sukiman. (2012). Pengembangan Media Pembelajaran. Yogyakarta: Pedagogia.

Trish Baker, J. C. (2010). Cooperative learning - a double-edged sword: A cooperative learning model for use with diverse student groups (pp. 257-268, Intercultural Education 21(3) June). pp. 257-268, Intercultural Education 21(3) June. https:// doi.org/10.1080/14675981003760440.

Vittrup, B. (2016). Early Childhood Teachers ' Approaches to Multicultural Education \& Perceived Barriers to Disseminating Anti-Bias Messages. Multicultural Education, 23(3-4), 37-41.

Wibisono, Y. (2009). Metode Statistik (p. 638). Yogyakarta: Gadjah Mada University Press. 